\title{
Can a Compact Pre-Filled Auto-Disable Injection System (cPAD) Save Costs for DTP-HepB-Hib Vaccine as Compared with Single-Dose (SDV) and Multi-Dose Vials (MDV)? Evidence from Cambodia, Ghana, and Peru
}

\author{
Cyril Nogier • Patrick Hanlon • Karin Wiedenmayer • \\ Nicolas Maire
}

Published online: 29 January 2015

(c) The Author(s) 2015. This article is published with open access at Springerlink.com

\begin{abstract}
Background A compact pre-filled auto-disable injection (cPAD) presentation is being developed for the fully liquid pentavalent DTP-HepB-Hib vaccine. A cost analysis (CA) to compare this presentation with the presently used singledose vial (SDV) and multi-dose vial (MDV) was conducted in Cambodia, Ghana, and Peru.

Methodology The CA included the development of an excel-based costing model and considered the costs of vaccine, safe injection equipment, procurement, storage, transport and distribution, vaccine administration by health staff, medical waste management, start-up activities, as well as coverage, birth cohort, vaccine, and safe injection equipment wastage rates. The outcome was the change in cost per pentavalent fully immunized child (PFIC) for a switch to cPAD. Field visits to health facilities, and interviews with key informants from immunization services and regulatory authorities, were conducted to collect data and to test the costing model in country context. Cost data were also obtained from manufacturers, published price lists, and author estimates. A sensitivity analysis (SA) was conducted to explore possible variations in values of data collected.
\end{abstract}

Electronic supplementary material The online version of this article (doi:10.1007/s40801-015-0010-0) contains supplementary material, which is available to authorized users.

C. Nogier $(\bowtie) \cdot$ P. Hanlon · K. Wiedenmayer · N. Maire Swiss Tropical and Public Health Institute, Socinstrasse 57, P.O. Box, 4002 Basel, Switzerland

e-mail: cyril.nogier@unibas.ch

N. Maire

University of Basel, Petersplatz 1, P.O. Box, 4003 Basel, Switzerland
Results Based on vaccine price trends estimated for 2016, cPAD is less costly in Ghana [incremental cost per PFIC: \$US-0.59 $(-6.46 \%)$ ] than the current presentation (tendose MDV) and in Peru (SDV): \$US-0.89 (-7.14\%). In Cambodia, cPAD is more costly than SDV: \$US +0.33 $(+3.90 \%)$.

Discussion and Conclusion The most significant cost item per PFIC is the vaccine (reflecting wastage rates) in all presentations. The dominance of the vaccine price per dose and, to a lesser extent, the wastage rates in the incremental cost per PFIC show potential to simplify future analyses. Other relevant considerations at country level for a change of presentation include the potential for improved safety with cPAD, planned introduction of other vaccines, environmental and safety issues, and financial sustainability.

\section{Key Points}

The compact pre-filled auto-disable injection system (cPAD), currently under development, is the less costly presentation of the DTP-HepB-Hib vaccine in Ghana and Peru as compared with the presently used presentation, respectively multi-dose vial (MDV) and single-dose vial (SDV). In Cambodia, the currently used SDV would save costs as compared with cPAD.

The largest cost item is the vaccine, reflecting wastage rates.

At country level, a number of factors, such as environmental and safety concerns, and financing sustainability, may also be important when a change in presentation is considered. 


\section{Introduction}

Immunizations against childhood communicable diseases are among the most cost-effective public health interventions [1]. Analyses of the costs and costeffectiveness of introducing new vaccines and simplified delivery systems are important to determine the level of resources required to improve immunization programs, increase coverage, and optimize the allocation of scarce resources [2].

Combination vaccines present advantages compared with monovalent vaccines in terms of fewer injections for children, ease of administration leading to reduced health worker time, and possibly increased coverage [3]. Thus, combining vaccines can reduce child mortality and help reach the Millennium Development Goal 4 [4]. Technological improvements such as fully liquid combination vaccines in a single injection have been developed to rationalize vaccine delivery and to simplify supply and administration of vaccines. The availability of vaccines using easy-to-use technologies should strengthen immunization programs and contribute to increasing health service performance [5]. Furthermore, simpler vaccine delivery reduces the potential for handling errors, facilitates training, and enables vaccination programs to reach children in remote areas [6].

Uniject $^{\mathrm{TM}}$ is a compact pre-filled auto-disable injection (cPAD) developed in the late 1980s by Becton Dickinson in collaboration with the Program for Appropriate Technology in Health (PATH), with the objectives of reducing transmission of infection caused by reusing and/or improperly sterilizing syringes and needles, reducing vaccine wastage, improving access to immunization services, and increasing coverage through simplifying the delivery system [6]. cPAD devices have been used in Asia, Africa, and Latin America since 1991 to administer vaccines (tetanus toxoid, hepatitis B, and hepatitis A) [7, 8] and drugs (cyclofem, oxytocin, etc.) [9, 10]. They potentially present several key advantages over the single-dose vial (SDV) and multi-dose vial (MDV), such as low wastage rate, reduced waste management costs, very limited risk of contamination, ease of use, and reduced administration time [3, 8] (PATH 2011, pentavalent in Uniject market research. Final report, unpublished) (PATH 2012, planning for the introduction of Quinvaxem in Uniject. Healthcare waste management considerations. Draft report, unpublished).

The decision to introduce a new vaccine and/or change the format of presentation generally may be influenced by (1) vaccine price, due to the lower price per dose of the MDV compared with the SDV or cPAD such as Uniject ${ }^{\mathrm{TM}}$, (2) cold chain requirements, with the MDV occupying less space per dose than the SDV or CPAD, (3) vaccine wastage, because MDVs have significantly higher wastage rates than SDVs and cPADs, (4) safety and contamination risk, as with SDV and cPAD it is not necessary to draw several doses from the same vial, (5) health staff time, as a consequence of less time required to administer the vaccine with a cPAD than with the other presentations, and (6) medical waste because of the potential for reducing the volume and weight of medical waste with $\mathrm{CPAD}$, as glass vials and syringes can be eliminated from the waste disposal chain, and more cPAD than syringes can be disposed of in one safety box.

The economic and programmatic consequences of introducing a new delivery system in national immunization programs are affected by the characteristics of these programs, including their cost structure and efficiency level [11]. A cost analysis (CA) of the various presentations of the pentavalent ${ }^{1}$ vaccine was conducted in Ghana, Peru, and Cambodia to provide evidence on the costs and benefits of switching from the current pentavalent presentation (SDV or MDV ten dose) to cPAD.

\section{Methods}

The main estimated outcome was the cost per pentavalent fully immunized child (PFIC) for each presentation, where the difference in cost per PFIC also included the cost of switching (start-up cost) from the currently used presentation to cPAD. The population targeted for the pentavalent vaccine was children less than 1 year of age. The estimated annual birth cohort was used in the calculations based on the country population, growth rate, and natality rate. Different time horizons were considered, depending on the country's respective immunization program planning process: 5 years in Peru and Ghana and 8 years in Cambodia. It was not an objective to compare costs between countries, but rather to use and test the model in three different country contexts. The countries were selected to represent different continents, socio-economic conditions and current vaccine presentations. The CA took the perspective of the Ministry of Health (MoH) and considered the full costs of each vaccine presentation, whatever the sources of financing from point of entry into the country through to delivery of the vaccine to children, as far as cost data were available at different levels. In Ghana, the study adopted the more restrictive perspective of the Expanded Program on Immunization (EPI) rather than the wider $\mathrm{MoH}$ due to the lack of readily available $\mathrm{MoH}$ detailed costing data for the EPI. The MoH costing data did not differentiate by program for such cost items as transport, storage, etc.

\footnotetext{
${ }^{1}$ In the rest of this paper "pentavalent" is used to refer to the "DTPHepB-Hib vaccine".
} 
cPAD was compared with the currently used presentation: SDV in Peru and Cambodia and MDV (ten doses) in Ghana. A Microsoft ${ }^{\circledR}$ Excel-based model was developed to compute the costs and the cost per PFIC of administering the pentavalent in three different possible presentations (SDV, MDV-ten dose, and cPAD). The model was designed as a simple tool requiring limited data and providing a simple cost-per-PFIC ratio (refer to Table 1 for all the parameters considered) in order to be usable by the immunization program managers. Where data were available, the models for each country were also populated to allow comparison between all possible presentations, as in Ghana with the SDV. We computed the incremental costs/ savings of using another format of the pentavalent vaccine compared with the currently used presentation. This approach assumes that the organizational infrastructure already exists and the general administrative costs should not be affected largely by the change in vaccine presentation.

The following costs were estimated:

- vaccine and safe injection equipment plus their management costs.

- storage, transport, and distribution of the vaccines and safe injection material.

- vaccine administration by health staff.

- medical waste management.

- start-up costs for the change and roll-out of a new vaccine delivery system.

The vaccine prices for the cPAD and SDV utilized in the CA were provided by the pentavalent manufacturer that currently produces an SDV and that will launch CPAD in 2016; both prices are forecasts for that year. The vaccine price used for the MDV is the lowest vaccine price contracted with suppliers by UNICEF for 2016. The costs of storage, transportation, and distribution of vaccines and safe injection material were estimated based on available cost data in each country and were otherwise estimated based on the underlying assumption that the incremental costs of each parameter compared with the base case would reflect the relative importance of each parameter in relation to the others. This assumption was necessary because vaccine-specific and health system level (central, regional, district, health facility) costing data were mostly not available. The sensitivity analysis (SA) confirmed that this assumption is valid over wide ranges for each of these parameters. The start-up costs were depreciated on a linear basis over their life span (estimated at 3 years for training costs, which would need to be repeated due primarily to staff turnovers and as a one-time investment for the other items). The capital costs of increasing the cold chain capacity in these countries were not included, as it was assumed, based on discussions during the country visits, that there was sufficient capacity available for introducing the pentavalent vaccine in cPAD. All costs and outcomes were discounted at $3 \%$ per annum. Inflation was not considered in the analysis, though the ranges used in the SA were much greater than any reasonable inflation rate might be. The results are expressed in \$US, year 2013 values. The summary of the parameters used is detailed in Table 1. The source of parameter values and how they were estimated is detailed in Table 6 of the Electronic Supplementary Material 1.

Due to the large uncertainty of the value of many of the parameters, both univariate and probabilistic SAs were performed [12] to test the robustness of the predictions, and to identify the main contributors to uncertainty in the predicted cost per PFIC. The univariate SA used low and high absolute estimates of each parameter against the background of best estimate values of the remaining parameters to predict the incremental cost per PFIC. For the probabilistic SA, parameters were sampled independently and simultaneously from statistical distributions (Table 2). Here, regression analysis was used to estimate the contribution of each parameter to the uncertainty of the incremental cost per PFIC. The contribution of a parameter was measured as the difference in the predicted incremental cost at the 2.5 and $97.5 \%$, and visualized in a tornado diagram [13]. The analysis was based on a total of 1,000 model runs.

\section{Results}

\section{Results of the Cost Analysis}

The main results of the analysis in the three countries are summarized in Tables 3 and 4 in terms of number of PFIC, and absolute and incremental costs (total and per PFIC) of cPAD compared with the currently used pentavalent presentations.

The CA of the pentavalent vaccine shows that the least costly presentation varies depending on the country context (Table 1). In Ghana and Peru, cPAD is the least costly presentation and leads to savings in terms of vaccines and safe injection equipment procurement, medical waste management, dry storage, and transportation. In Cambodia, cPAD results in incremental costs due to the higher price per dose of the new presentation. In all countries, the startup costs for training of health staff and monitoring and evaluation activities represent a small share (below $2 \%$ ) of the total costs of a new presentation such as cPAD. Additional capital investment would not be required, as the existing cold chain capacity in all countries was estimated to be sufficient to accommodate the increased volume required by the new cPAD presentation. 
Table 1 Specific parameter values used in the cost analysis ${ }^{\mathrm{a}}$

\begin{tabular}{|c|c|c|c|}
\hline Parameters in the model & Cambodia & Ghana & Peru \\
\hline Time horizon (years) & 8 & 5 & 5 \\
\hline Population at start year $(2011)^{\mathrm{b}}$ & $14,962,591$ & $26,009,711$ & $30,135,875$ \\
\hline Natality rate $(2011)^{\mathrm{b}}$ & 2.42 & 4.0 & 1.93 \\
\hline Growth rate of population for $2013-2017(\%)^{\mathrm{b}}$ & 1.2 & 2.4 & 1.1 \\
\hline Immunization coverage of the pentavalent $(\%)$ & 94 & $86 \%$ & 91 \\
\hline $\begin{array}{l}\text { Number of pentavalent injections in children aged } \\
0-1 \text { year }\end{array}$ & 3 & 3 & 3 \\
\hline Price of pentavalent in base case-FCA & $2.26(\mathrm{SDV})$ & 1.95 (MDV-10) & $2.40(\mathrm{SDV})$ \\
\hline Price of pentavalent in $\mathrm{cPAD}-\mathrm{FCA}$ & 2.41 & 2.41 & 2.55 \\
\hline $\begin{array}{l}\text { Taxes on FCA for vaccine procured through UNICEF } \\
(\%)\end{array}$ & 15.5 & $\begin{array}{l}\text { 4.5 handling charges; } 8.0 \\
\text { freight insurance inspection }\end{array}$ & 40.5 \\
\hline $\begin{array}{l}\text { Procurement management costs in } \% \text { of the cost of } \\
\text { vaccines and safe injection equipment }\end{array}$ & 3.5 & NA & 0.1 \\
\hline Price of syringes-FCA & $0.05(0.5 \mathrm{ml} \mathrm{AD})$ & $0.04(0.5 \mathrm{ml} \mathrm{AD})$ & $0.24(1.0 \mathrm{ml} \mathrm{AR})$ \\
\hline Price of safety boxes-FCA & 0.60 & 0.48 & 0.50 \\
\hline Wastage rate $(\%)$ of pentavalent in SDV & 4 & 25 (MDV-10) & 5 \\
\hline Wastage rate $(\%)$ of pentavalent in $\mathrm{cPAD}$ & 2 & 2 & 2 \\
\hline 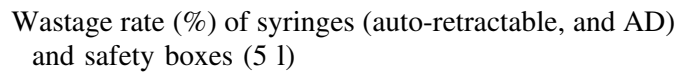 & 10 & 10 & 10 \\
\hline Volume of the pentavalent in base-case format $\left(\mathrm{cm}^{3}\right)$ & $10.28(\mathrm{SDV})$ & $2.60(\mathrm{MDV}-10 \mathrm{dose})$ & $10.28(\mathrm{SDV})$ \\
\hline Volume of the pentavalent in $\mathrm{cPAD}\left(\mathrm{cm}^{3}\right)$ & 15.18 & 15.18 & 15.18 \\
\hline Volume of the syringes $\left(\mathrm{cm}^{3}\right)$ & $42.90(0.5 \mathrm{ml} \mathrm{AD})$ & $42.90(0.5 \mathrm{ml} \mathrm{AD})$ & $46.15(1.0 \mathrm{ml} \mathrm{AR})$ \\
\hline \multicolumn{4}{|l|}{ Volume of the safety boxes $\left(\begin{array}{ll}5 & 1\end{array}\right)$} \\
\hline Packed $\left(\mathrm{cm}^{3}\right)$ & 694 & 694 & 694 \\
\hline Unpacked $\left(\mathrm{cm}^{3}\right)$ & 5,840 & 5,840 & 5,840 \\
\hline Weight $(\mathrm{g})$ of the safety boxes $(5 \mathrm{l})$ & 326.50 & NA & 326.50 \\
\hline Number of cPAD devices per safety box $\left(\begin{array}{ll}5 & 1\end{array}\right)$ & 500 & 500 & 500 \\
\hline Number of syringes per safety box $\left(\begin{array}{ll}5 & 1\end{array}\right)$ & $190(0.5 \mathrm{ml} \mathrm{AD})$ & $190(0.5 \mathrm{ml} \mathrm{AD})$ & $300(1.0 \mathrm{ml} \mathrm{AR})$ \\
\hline $\begin{array}{l}\text { Weight of the pentavalent vaccine in cPAD } \\
\text { (filled/empty cPAD) }\end{array}$ & $4.14 / 1.17 \mathrm{~g}$ & $4.14 / 1.17 \mathrm{~g}$ & $4.14 / 1.17 \mathrm{~g}$ \\
\hline $\begin{array}{l}\text { Weight }(\mathrm{g}) \text { of the pentavalent vaccine vial } \\
\text { (filled/empty vial) }\end{array}$ & $5.44 / 2.65(\mathrm{SDV})$ & 8.87/3.87 (MDV-10) & $5.44 / 2.65(\mathrm{SDV})$ \\
\hline Weight $(\mathrm{g})$ of syringe secondary packaging/alone & $4.80 / 2.90(0.5 \mathrm{ml} \mathrm{AD})$ & $4.80 / 2.90(0.5 \mathrm{ml} \mathrm{AD})$ & $4.50 / 2.80(1.0 \mathrm{ml} \mathrm{AR})$ \\
\hline $\begin{array}{l}\text { Transportation costs of vaccine from central to } \\
\text { provincial level }\end{array}$ & $36 / \mathrm{m}^{3}$ & $50 / \mathrm{m}^{3}$ & $3 / \mathrm{kg}$ \\
\hline $\begin{array}{l}\text { Transportation costs-not refrigerated from central } \\
\text { to provincial level }\end{array}$ & $36 / \mathrm{m}^{3}$ & $10 / \mathrm{m}^{3}$ & $1.5 / \mathrm{kg}$ \\
\hline $\begin{array}{l}\text { Refrigerated storage costs of vaccines }\left(2-8^{\circ} \mathrm{C}\right) \\
\text { at central level }\left(\text { per } \mathrm{m}^{3}\right)\end{array}$ & 357 & 1,000 & 1,000 \\
\hline Dry storage costs at central level $\left(\right.$ per $\left.\mathrm{m}^{3}\right)$ & 14 & 10 & 277 \\
\hline Labor costs for nurse at health center (\$US/month) & 110 & 1,035 & 682 \\
\hline Hours worked per month per health staff at health center & NA & 147 & NA \\
\hline Working days/year & 236 & 220 & 220 \\
\hline Working hours/day & 8 & 8 & 8 \\
\hline \multicolumn{4}{|l|}{ Staff time for one injection } \\
\hline With SDV/MDV & $19.3 \mathrm{~s}(\mathrm{SDV})$ & $15.3 \mathrm{~s}(\mathrm{MDV})$ & $19.3 \mathrm{~s}(\mathrm{SDV})$ \\
\hline With cPAD & $7.5 \mathrm{~s}(\mathrm{cPAD})$ & $7.5 \mathrm{~s}(\mathrm{cPAD})$ & $7.5 \mathrm{~s}(\mathrm{cPAD})$ \\
\hline Costs of contaminated waste collection and elimination & $1 / \mathrm{kg}$ & $5 / \mathrm{m}^{3}$ & $1.5 / \mathrm{kg}$ \\
\hline
\end{tabular}


Table 1 continued

\begin{tabular}{llll}
\hline Parameters in the model & Cambodia & Ghana & Peru \\
\hline Start-up costs for cPAD_training of health staff & $\begin{array}{l}150,000 \text { for training; } \\
10,000 \text { for } \\
\text { supervision, } \\
\text { monitoring and }\end{array}$ & $\begin{array}{l}166,309 \text { for training; 12,833 } \\
\text { for information guide }\end{array}$ & $\begin{array}{c}87,815 \text { for training; } \\
15,000 \text { for } \\
\text { supervision, } \\
\text { monitoring, and } \\
\text { evaluation }\end{array}$ \\
Discounting rate $(\%)$ & 3 & 3 & 3 \\
\hline
\end{tabular}

$A D$ auto-disable, $A R$ auto-retractable, $c P A D$ compact pre-filled auto-disable injection system, $F C A$ free carrier (incoterm), $M D V$ multi-dose vial, $N A$ not applicable, $S D V$ single-dose vial

${ }^{a}$ All costs are presented in \$US

b The variables 'population at start year', 'natality rate', and 'growth rate of population' result in a different birth cohort per year over the time horizon for each country

Table 2 Parameter value ranges and their distribution utilized for the sensitivity analyses ${ }^{\mathrm{a}}$

\begin{tabular}{|c|c|c|c|}
\hline Parameters & Cambodia & Ghana & Peru \\
\hline Price of the pentavalent in $\mathrm{cPAD}$ per dose & $2.05-2.41-2.95$ (triangular) & $2.05-2.41-3.40$ (triangular) & $2.45-2.55-3.35$ (triangular) \\
\hline Price of the pentavalent per dose & $\begin{array}{l}\text { (SDV) } 1.90-2.26-2.80 \\
\quad \text { (triangular) }\end{array}$ & $\begin{array}{l}\text { (MDV-10) } 1.75-1.95-2.20 \\
\text { (triangular) }\end{array}$ & $\begin{array}{l}\text { (SDV) 2.30-2.40-3.20 } \\
\text { (triangular) }\end{array}$ \\
\hline $\begin{array}{l}\text { Coverage of cPAD and M/SDV presentation } \\
(\%)\end{array}$ & 92-94-95 (triangular) & 80-86-97 (triangular) & 90-91-95 (triangular) \\
\hline Wastage rate of the pentavalent in cPAD (\%) & $1-2-3$ (triangular) & $1-2-3$ (triangular) & $1-2-3$ (triangular) \\
\hline Wastage rate of the pentavalent (\%) & (SDV) $1-4-5$ (triangular) & $\begin{array}{l}\text { (MDV-10) } 10-25-40 \\
\text { (triangular) }\end{array}$ & (SDV) $1-5-6$ (triangular) \\
\hline $\begin{array}{l}\text { Wastage rate of the syringes and safety boxes } \\
(\%)\end{array}$ & $5-10-12$ (triangular) & 5-10-12 (triangular) & 5-10-12 (triangular) \\
\hline Dry storage costs at central level $\left(\right.$ per $\left.\mathrm{m}^{3}\right)$ & 14-40 (uniform) & $1-10-50$ (triangular) & $150-277-500$ (triangular) \\
\hline $\begin{array}{l}\text { Dry transportation costs from central to } \\
\text { regional level }\end{array}$ & $\begin{array}{l}\text { Per } \mathrm{m}^{3} \\
36-100 \text { (uniform) }\end{array}$ & $\begin{array}{l}\text { Per } \mathrm{m}^{3} \\
1-10-50 \text { (triangular) }\end{array}$ & $\begin{array}{l}\text { Per kg } \\
1-1.5-4 \text { (triangular) }\end{array}$ \\
\hline $\begin{array}{l}\text { Refrigerated storage costs at central level } \\
\left(\text { per } \mathrm{m}^{3}\right)\end{array}$ & 357-800 (uniform) & $700-1,000-1,200$ (triangular) & $\begin{array}{l}700-1,000-1,200 \\
\text { (triangular) }\end{array}$ \\
\hline $\begin{array}{l}\text { Transportation of vaccines from central to } \\
\text { regional level }\end{array}$ & $\begin{array}{l}\text { Per } \mathrm{m}^{3} \\
36-100 \text { (uniform) }\end{array}$ & $\begin{array}{l}\text { Per } \mathrm{m}^{3} \\
10-50-100 \text { (triangular) }\end{array}$ & $\begin{array}{l}\text { Per kg } \\
3-5 \text { (Uniform) }\end{array}$ \\
\hline Elimination costs of contaminated waste & $\begin{array}{l}\text { Per kg } \\
1.0-3.0 \text { (uniform) }\end{array}$ & $\begin{array}{l}\text { Per } \mathrm{m}^{3} \\
1.0-5.0-25.0 \text { (triangular) }\end{array}$ & $\begin{array}{l}\text { Per kg } \\
0.5-1.5-3.0 \text { (triangular) }\end{array}$ \\
\hline Start-up costs of cPAD annualized & $\begin{array}{l}0-430,781-576,041 \\
\quad \text { (triangular) }\end{array}$ & $\begin{array}{l}1-179,142-350,000 \\
\text { (triangular) }\end{array}$ & $\begin{array}{l}0-185,589-190,630 \\
\quad \text { (triangular) }\end{array}$ \\
\hline
\end{tabular}

$c P A D$ compact prefilled auto-disable injection system, $M D V$ multi-dose vial, $S D V$ single-dose vial

a All costs are presented in \$US. Triangular distributions are presented as lower-mode-upper

The estimated costs per PFIC for all presentations shows that in all three countries, the most important cost item of the cost per PFIC is the vaccine (including vaccine wastage) in any presentation, accounting for $85 \%$ of total cost in Peru and over $97 \%$ in the two other countries, with the cPAD presentation leading to a higher share of the total vaccine costs compared with SDV and MDV (Table 4).
Results of the Sensitivity Analyses

The univariate SA shows that, under the assumption of the values of the parameters in Table 1, the least costly presentation in almost all cases is the SDV in Cambodia, and the cPAD in Ghana and Peru. This confirms the robustness of the results of the evaluation. The probabilistic SA (Fig. 1) illustrates the dominance of the respective vaccine 
Table 3 Estimated outcomes, total and incremental cost (total and per pentavalent fully immunized child) for the switch from current presentation to compact prefilled auto-disable injection system ${ }^{\mathrm{a}}$

\begin{tabular}{llll}
\hline Outcomes/country & Cambodia & Ghana & Peru \\
\hline Period & 8 years, 2013-2020 & 5 years, 2013-2017 & 5 years, 2013-2017 \\
Birth cohort at start & 362,095 & $1,040,388$ & 581,622 \\
Birth cohort, cumulative, undiscounted (discounted) & $3,021,705$ & $5,457,700$ & $2,973,392$ \\
& $(2,725,911)$ & $(5,141,689)$ & $(2,803,327)$ \\
Number of PFIC cumulative, undiscounted (discounted) & $2,840,402$ & $4,693,622$ & $2,705,786$ \\
& $(2,562,356)$ & $(4,421,852)$ & $(2,551,027)$ \\
Current presentation & SDV & MDV-10 dose & $31,745,567$ \\
Total costs of the current presentation & $21,526,847$ & $40,062,615$ & $-2,266,261(-7.14 \%)$ \\
Total incremental costs in nominal value and $\%$ & $+840,007(+3.90 \%)$ & $-2,590,026(-6.46 \%)$ & 12.44 \\
Cost per PFIC of the current presentation & 8.40 & 9.06 & $-0.59(-6.46 \%)$ \\
Incremental cost per PFIC in nominal value and $\%$ & $+0.33(+3.90 \%)$ & $-0.89(-7.14 \%)$ &
\end{tabular}

$M D V$ multi-dose vial, PFIC pentavalent fully immunized child, $S D V$ single-dose vial

${ }^{\text {a }}$ All costs are presented in \$US, year 2013 values

Table 4 Estimated absolute and incremental costs per pentavalent fully immunized child for the switch from current presentation to compact prefilled auto-disable injection system ${ }^{\mathrm{a}}$

\begin{tabular}{|c|c|c|c|c|c|c|c|c|c|c|c|c|}
\hline \multirow{3}{*}{$\begin{array}{l}\text { Disaggregated costs } \\
\text { per PFIC }\end{array}$} & \multicolumn{4}{|c|}{ Cambodia, 2013-2020 } & \multicolumn{4}{|c|}{ Ghana 2013-2017 } & \multicolumn{4}{|c|}{ Peru, 2013-2017 } \\
\hline & \multicolumn{2}{|c|}{$\begin{array}{l}\text { Absolute } \\
\text { costs }\end{array}$} & \multicolumn{2}{|c|}{$\begin{array}{l}\text { Incremental costs } \\
\text { of cPAD vs. SDV }\end{array}$} & \multicolumn{2}{|c|}{$\begin{array}{l}\text { Absolute } \\
\text { costs }\end{array}$} & \multicolumn{2}{|c|}{$\begin{array}{l}\text { Incremental costs } \\
\text { of cPAD vs. MDV }\end{array}$} & \multicolumn{2}{|c|}{$\begin{array}{l}\text { Absolute } \\
\text { costs }\end{array}$} & \multicolumn{2}{|c|}{$\begin{array}{l}\text { Incremental costs } \\
\text { of cPAD vs. SDV }\end{array}$} \\
\hline & SDV & $\mathrm{cPAD}$ & $\begin{array}{l}\text { Nominal } \\
\text { values }\end{array}$ & $\%$ & MDV & cPAD & $\begin{array}{l}\text { Nominal } \\
\text { values }\end{array}$ & $\%$ & SDV & cPAD & $\begin{array}{l}\text { Nominal } \\
\text { values }\end{array}$ & $\%$ \\
\hline Cost per PFIC & 8.40 & 8.73 & 0.33 & +3.90 & 9.06 & 8.47 & -0.59 & -6.46 & 12.44 & 11.56 & -0.89 & -7.14 \\
\hline $\begin{array}{l}\text { Total purchase price of } \\
\text { vaccines (excluding } \\
\text { procurement } \\
\text { management) }\end{array}$ & 8.16 & 8.52 & 0.36 & +4.46 & 8.78 & 8.30 & -0.48 & -5.42 & 10.65 & 10.97 & 0.32 & +3.00 \\
\hline $\begin{array}{l}\text { Procurement management } \\
\text { costs of vaccines }{ }^{\mathrm{b}}\end{array}$ & 0.01 & 0.01 & 0.00 & +4.46 & 0.00 & 0.00 & 0.00 & 0.00 & 0.37 & 0.38 & 0.01 & +3.00 \\
\hline $\begin{array}{l}\text { Safe injection equipment } \\
\text { (excluding procurement } \\
\text { management) }\end{array}$ & 0.19 & 0.00 & -0.19 & -97.61 & 0.18 & 0.01 & -0.18 & -95.84 & 1.13 & 0.00 & -1.13 & -99.59 \\
\hline $\begin{array}{l}\text { Procurement management } \\
\text { costs of safe injection } \\
\text { equipment }\end{array}$ & 0.00 & 0.00 & 0.00 & -97.61 & 0.00 & 0.00 & 0.00 & 0.00 & 0.04 & 0.00 & -0.04 & -99.59 \\
\hline Start-up costs & 0.00 & 0.17 & 0.17 & -100.00 & 0.00 & 0.08 & 0.08 & 0.00 & 0.00 & 0.07 & 0.07 & -100.00 \\
\hline Staff cost total & 0.01 & 0.00 & 0.00 & -61.14 & 0.09 & 0.04 & -0.04 & -50.98 & 0.07 & 0.03 & -0.05 & -61.14 \\
\hline Total cold chain cost & 0.01 & 0.02 & 0.01 & +44.65 & 0.01 & 0.05 & 0.04 & +346.82 & 0.03 & 0.05 & 0.01 & +43.15 \\
\hline Total dry storage cost & 0.00 & 0.00 & 0.00 & -97.02 & 0.00 & 0.00 & -0.00 & -97.70 & 0.04 & 0.00 & -0.04 & -97.14 \\
\hline $\begin{array}{l}\text { Total transportation cost } \\
\text { refrigerated }\end{array}$ & 0.00 & 0.00 & 0.00 & +44.65 & 0.00 & 0.00 & 0.00 & +346.82 & 0.05 & 0.04 & -0.01 & -26.23 \\
\hline $\begin{array}{l}\text { Total transportation cost } \\
\text { dry }\end{array}$ & 0.01 & 0.00 & -0.01 & -97.02 & 0.00 & 0.00 & -0.00 & -97.70 & 0.03 & 0.00 & -0.02 & -88.40 \\
\hline Disposal cost & 0.02 & 0.01 & -0.01 & -63.80 & 0.00 & 0.00 & -0.00 & -65.10 & 0.02 & 0.01 & -0.01 & -56.58 \\
\hline
\end{tabular}

$c P A D$ compact prefilled auto-disable injection system, $M D V$ multi-dose vial, $P F I C$ pentavalent fully immunized child, $S D V$ single-dose vial

a All costs are presented in \$US, year 2013 values

b The vaccine prices used are expected prices in 2016 comparable to major procurement prices 

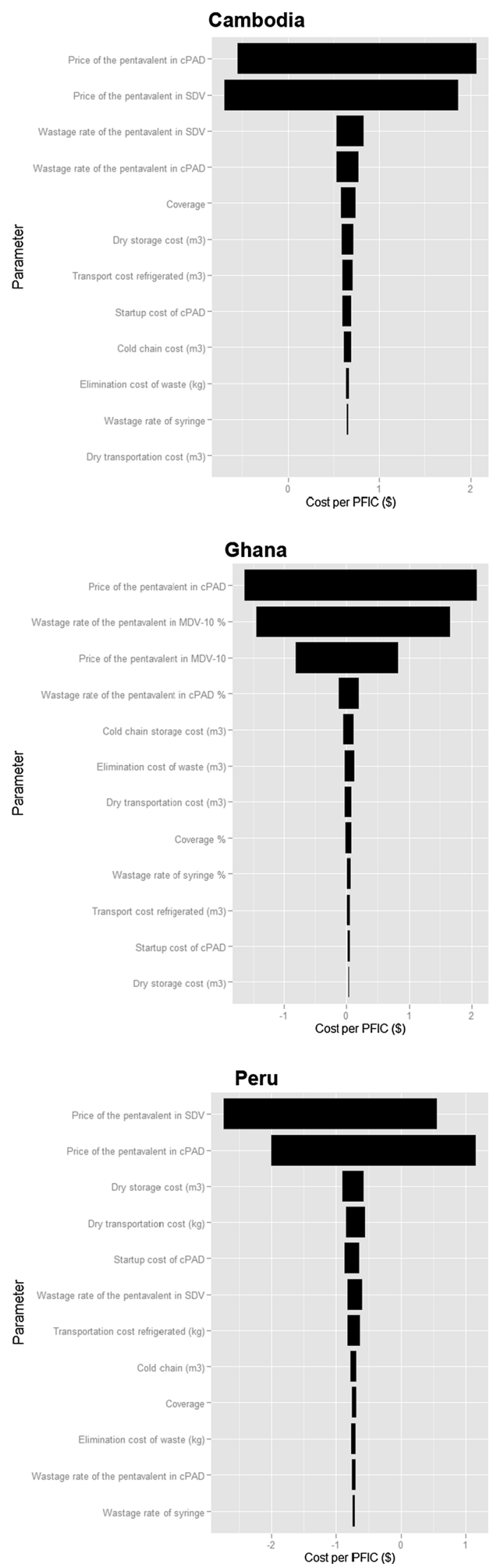

4 Fig. 1 Contribution of input values on the uncertainty of the predicted incremental cost per pentavalent fully immunized child of compact prefilled auto-disable injection system versus single-dose vial in Cambodia and Peru, ten-dose multi-dose vial in Ghana. $c P A D$ compact prefilled auto-disable injection system, $M D V$ multi-dose vial, PFIC pentavalent fully immunized child, $S D V$ single-dose vial. Program used: R, plots are in wmf format

purchase prices (cPAD and SDV, MDV) in the uncertainty in predicting the incremental cost per PFIC in all three countries. Some other parameters (i.e. wastage rate of the pentavalent in SDV in Cambodia and Peru, start-up costs in Cambodia, and wastage rate of the pentavalent in CPAD in Ghana, respectively) add to the uncertainty to a lesser extent. In Ghana, the wastage rates of MDV-ten doses are the second-most important cause of uncertainty.

In all three countries, varying the discount rate $(0,7 \%)$ did not cause any change in the least costly presentation.

\section{Other Findings}

Outcomes pertaining to storage, transport, and medical waste of the different presentations of the pentavalent vaccine show that the cPAD would lead to an incremental cold chain requirement as compared with the SDV and MDV. In Ghana, the cPAD would cumulatively require an additional $169.3 \mathrm{~m}^{3}(+346.8 \%)$ (average per year $33.9 \mathrm{~m}^{3}$ based on the additional volume of the cPAD compared with the base-case MDV-ten dose) of cold chain over 5 years, while in Cambodia and Peru the incremental required cold chain capacity would be $40.7 \mathrm{~m}^{3}(+44.6 \%)$ over 8 years (average per year $5.1 \mathrm{~m}^{3}$ based on the additional volume of the cPAD compared with the base-case SDV) and $37.9 \mathrm{~m}^{3}(+43.1 \%)$ (average per year $7.6 \mathrm{~m}^{3}$ based on the additional volume of the cPAD compared with the base-case SDV) over 5 years, respectively (Table 5). These incremental volumes apply to the whole system and were not broken down per level. On the other hand, cPAD would save dry storage volume and drastically reduce medical waste generated. For instance, cPAD presentation would allow saving 4,406,257 doses (or 187,744 glass vials) and 15,645,407 syringes, representing a total of $347.85 \mathrm{~m}^{3}$ of medical waste in Ghana over 5 years, by removing glass vials from the medical waste production.

\section{Discussion}

To our knowledge, this is the first CA comparing the cPAD with the SDV and MDV-ten dose presentations. It shows that, in all three countries, the most important cost item of the cost per PFIC is the pentavalent vaccine in any presentation (including vaccine wastage) and that the cPAD 
Table 5 Incremental predictions (total and per pentavalent fully immunized child) of storage and medical waste generated by compact prefilled auto-disable injection system as compared with single-dose vials in Cambodia and Peru and versus multi-dose vials in Ghana over the respective time horizon

\begin{tabular}{lccc}
\hline Incremental predictions-total and per PFIC & $\begin{array}{l}\text { Cambodia } \\
\text { Incremental as } \\
\text { compared with SDV }\end{array}$ & $\begin{array}{l}\text { Ghana } \\
\text { Incremental as } \\
\text { compared with MDV }\end{array}$ & $\begin{array}{l}\text { Peru } \\
\text { Incremental as } \\
\text { compared with SDV }\end{array}$ \\
\hline Total incremental predictions over the considered period & $-427.33(-97.02)$ & $-706.15(-97.02)$ & $-424.59(-97.14)$ \\
Dry storage volume, $\mathrm{m}^{3}(\%)$ & $+40.74(+44.65)$ & $+169.30(+346.82)$ & $+37.90(+43.15)$ \\
Cold chain volume, $\mathrm{m}^{3}(\%)$ & $-210.51(-65.10)$ & $-347.85(-65.10)$ & $-87.59(-44.90)$ \\
Medical waste volume, $\mathrm{m}^{3}(\%)$ & $-29.05(-63.80)$ & $-48.01(-63.80)$ & $-20.46(-56.58)$ \\
Medical waste weight, tons $(\%)$ & & & -159.92 \\
Disaggregated incremental predictions per PFIC & -150.45 & -150.45 & +14.01 \\
Dry storage volume $\left(\mathrm{cm}^{3}\right)$ & +14.34 & +36.07 & -32.37 \\
Cold chain volume $\left(\mathrm{cm}^{3}\right)$ & -74.11 & -74.11 & -7.56 \\
Medical waste volume $\left(\mathrm{cm}^{3}\right)$ & -10.23 & -10.23 & \\
Medical waste weight $(\mathrm{g})$ & & & \\
\hline
\end{tabular}

$M D V$ multi-dose vial, $P F I C$ pentavalent fully immunized child, $S D V$ single-dose vial

can be less costly than the other presentations. Amongst the large number of economic evaluations of vaccines, few deal with the pentavalent vaccine; the most recent usually consider Hib vaccine to be a cost-effective intervention [14]. Specific parameters considered when comparing vaccine presentations are start-up costs [15], medical waste management [16], required health staff time for vaccine administration [17], in addition to other commonly considered parameters (price of vaccine and safe injection equipment, wastage rates, and cold chain requirements).

Other factors would influence the decision to switch to the cPAD for the pentavalent vaccine. Such a switch leads to substantial reductions in safe injection equipment required (no syringes are needed and fewer safety boxes are required), translating into reduced dry storage and transportation volume. Logistical issues for immunization programs relate notably to the volume per dose of the vaccine, which impacts on the required cold chain capacity for both distribution and storage because the volume of a unit dose of a vaccine in an MDV is smaller than in an SDV, which is in its turn smaller than in a pre-filled AD device [3]. Our study highlights the expected reduction in dry storage space and the greater requirements in terms of cold chain capacity.

In addition, the cPAD considerably reduces the volume of medical waste generated and eliminates glass vials and syringes from the waste stream. The vial size impacts on the volume of waste produced; SDVs generate more waste per dose than MDVs, and cPADs generate significantly less waste than SDVs and MDVs [3]. This aspect is critical in situations where not only health staff is exposed to contaminated waste but also communities because of frequent sub-standard waste management processes. Our findings show that such a reduction in medical waste can be expected in the three countries.

Other possible advantages of using the cPAD include a reduced number of needle stick injuries (not explored here). Also, vaccine withdrawal from a vial is not required with the cPAD, leading to reduced vial contamination and resulting disease transmission. It is commonly considered that SDVs are safer than MDVs [18] because of a reduced risk of cross contamination and risk of blood-borne disease transmission. In addition, the $\mathrm{CPAD}$ and $\mathrm{AD}$ syringes used with SDVs and MDVs offset the risks of reusing syringes.

Where a high investment in cold chain capacity is required, this could have a substantial effect on the cost structure of a switch to cPAD and the incremental cost or savings.

Lower-dose vials may reduce missed opportunities for immunization because health personnel have been shown to be reluctant to open a new MDV with a limited number of patients $[19,20]$. This attitude leads to a reduction in the coverage of immunization services in outreach sessions. Gaps in the existing body of literature exist concerning the impact of cPAD as compared with other delivery systems on immunization service coverage in clinical settings.

It has been recommended that countries consider having a mix of different presentations of the same vaccine, depending on the nature of the immunization session (small or large throughput of patients) and of the immunization strategies (fixed or outreach) [3, 21-23]. For instance, for expensive vaccines, SDVs would be more appropriate in small sessions while MDVs would be more suitable in larger sessions. These recommendations are based on the price of vaccines, wastage rates of vaccine presentation, cold chain requirements, and disposal. Some break-even 
CAs have been shown to be very country specific [21, 23]. However, the impact of different presentations of the same vaccine on logistics management has to be weighed carefully.

Perception studies showed a globally high acceptability of cPAD (specifically Uniject ${ }^{\mathrm{TM}}$ ) by health staff, who preferred it to syringes and vials due to practicality, dose accuracy, reduced contaminated waste, time savings, and increased patients' acceptability (PATH 2011, pentavalent in Uniject market research. Final report, unpublished) [9]. Disadvantages of cPAD were rarely reported and were related to possible needle stick injuries, increased refrigerated volume, and the inability to practice aspiration [10, 24, 25] (PATH 2011, pentavalent in Uniject market research. Final report, unpublished). High acceptance by patients was associated with less fear of injection with the device and perception of higher safety [6, 10, 24]. Most perception studies were conducted with medicines other than vaccines, in outreach settings, and with lay health workers. Several studies reported the potential of cPAD to increase coverage, notably for $\mathrm{HepB}$ immunization in outreach interventions using unrefrigerated vaccine $[6,7$, 26].

The likeliness of switching to cPAD is closely linked to its financing (including sustainability) and its impact on the whole EPI budget. While the Peruvian Government finances the pentavalent vaccine entirely, the Ghanaian and Cambodian Governments still depend at least partially upon donors (in both countries, the GAVI Alliance has been funding part of the introduction of the pentavalent vaccine and safe injection equipment and has provided vaccine introduction grants to cover start-up costs). A budget impact analysis (BIA) would usefully complement this $\mathrm{CA}$, as it is increasingly being recommended [27] and because the immunization schedules of individual countries change with the introduction of new vaccines. For instance, Cambodia has planned the introduction of the pneumococcal vaccine in 2015 and Peru introduced the inactivated polio vaccine (IPV) in 2013.

This CA of the pentavalent has a number of limitations. Every model is a simplification of reality and therefore cannot capture all possible factors, events, or outcomes. In addition, the CA is based on a model developed for this study which, requiring a limited amount of data, was intentionally simple in order to be usable by the immunization program managers. The model does not account for possible change over time in fertility and population growth rate, which will affect the size of the birth cohort and consequently the number of doses required. Further, vaccine coverage over time is static. As not all parameter data were easily available, the cost of transportation and storage is only reflected for national to provincial or regional level in all three countries. Thus, the study underestimates the benefits of SDV and MDV compared with CPAD in terms of cost of refrigerated storage and distribution of vaccines below the intermediary level. The benefits of storage and transportation of safe injection equipment associated with cPAD compared with other presentations have also not been reflected below the intermediary level and therefore savings associated with cPAD are underestimated. Also, values for the various parameters may vary in accuracy and reliability as the data required for our model were collected from a variety of sources, including records and interviews at various levels.

Nevertheless, as shown by both types of SA performed, the main influential factor on this CA is the price of the vaccine in all countries for which precise indicationsestimates for 2016 comparable with major procurement prices-were obtained from the manufacturer and the UNICEF published pentavalent price list. These findings imply that the framework of analysis presented here is applicable for other types of vaccines.

\section{Conclusion}

This study shows, based on vaccine price projections for 2016, that the introduction of the pentavalent in the cPAD is less costly in Peru and Ghana than the current vaccine presentation (SDV and MDV-ten doses, respectively), while in Cambodia the current SDV presentation remains less costly. One parameter that is not included in the evaluation, but which may be significant in countries where the cold chain capacity is more limited, is the capital cost of its expansion to accommodate the higher volume per PFIC associated with cPAD.

Furthermore, this study provides a CA model for analyzing a change in vaccine presentations that can be applied to various settings and vaccines other than the pentavalent. The model and the SA illustrate the dominance of the vaccine price per presentation, adjusted to reflect wastage rates as the main cost item of the CA. This indicates the potential to simplify future analyses by focusing only on cost and wastage of vaccine and safe injection materials. The difficulty of obtaining reliable costing data for many of these apparently less important parameters could thus be avoided.

However, for decision making and policy dialogue at country level, several other factors maybe equally as important as the incremental costs of the vaccine when considering shifting to a new presentation such as cPAD. These are mainly related to easier logistics management, environmental aspects such as reduced waste generated, potential for increased safety, financing sustainability, and budget impact. 
Acknowledgments The study methodology (including the data collection tool) was developed by $\mathrm{CN}, \mathrm{PH}, \mathrm{KW}, \mathrm{NM}$ and Karen Maigetter (KM) (Swiss TPH). NM supported the development of the $\mathrm{CA}$ model. Data collection was conducted by $\mathrm{CN}$ in Peru, $\mathrm{CN}$ and KW in Cambodia, and PH and KM in Ghana. CN, PH, KW, and NM analyzed the data. PH wrote the first draft of the article, which was reviewed by $\mathrm{CN}, \mathrm{KW}$, and NM. All authors agreed on the final draft.

Conflict of interest The study was funded by Crucell, which is developing a cPAD for the pentavalent vaccine. Crucell did not influence the identification, design, conduct, and reporting of the analysis.

Ethical standards The manuscript does not contain clinical study or patient data.

Open Access This article is distributed under the terms of the Creative Commons Attribution Noncommercial License which permits any noncommercial use, distribution, and reproduction in any medium, provided the original author(s) and the source are credited.

\section{References}

1. Brenzel L, Wolfson LJ, Fox-Rushby J, Miller M, Halsey NA. Vaccine-preventable diseases. In: Jamison DT, Breman JG, Measham AR, Alleyne G, Claeson M, Evans DB, et al., editors. Disease control priorities in developing countries. 2nd ed. New York: Oxford University Press and The World Bank; 2006. p. $389-412$.

2. World Health Organisation. WHO Guide for standardization of economic evaluation of immunization programmes. Geneva: WHO; 2008.

3. Drain PK, Nelson CM, Lloyd JS. Single-dose versus multi-dose vaccine vials for immunization programmes in developing countries. Bull World Health Organ. 2003;81(10):726-31.

4. Marshall GS, Happe LE, Lunacsek OE, Szymanski MD, Woods $\mathrm{CR}$, Zahn M, et al. Use of combination vaccines is associated with improved coverage rates. Pediatr Infect Dis J. 2007;26(6): 496-500.

5. Clements CJ, Wesselingh SL. The study methodology (including the data collection. Expert Rev Vaccines. 2005;4(3):281-7.

6. Sutanto A, Suarnawa I, Nelson C, Stewart T, Soewarso TI. Home delivery of heat-stable vaccines in Indonesia: outreach immunization with a prefilled, single-use injection device. Bull World Health Organ. 1999;77(2):119-26.

7. Levin CE, Nelson CM, Widjaya A, Moniaga V, Anwar C. The costs of home delivery of a birth dose of hepatitis B vaccine in a prefilled syringe in Indonesia. Bull World Health Organ. 2005;83(6):456-61.

8. PATH. A health tech historical profile: the Uniject device. Seattle: PATH; 2005.

9. Althabe F, Mazzoni A, Cafferata ML, Gibbons L, Karolinski A, Armbruster D, et al. Using Uniject to increase the use of prophylactic oxytocin for management of the third stage of labor in Latin America. Int J Gynaecol Obstet. 2011;114(2):184-9.

10. Bahamondes L, Marchi NM, Cristofoletti ML, Nakagava HM, Pellini E, Araujo F, et al. Uniject ${ }^{\circledR}$ as a delivery system for the once-a-month injectable contraceptive Cyclofem $^{\circledR}$ in Brazil. Contraception. 1996;53(2):115-9.

11. Hydea TB, Dentza H, Wang SA, Burchett HE, Mounier-Jack S, Mantelb CF, et al. The impact of new vaccine introduction on immunization and health systems: a review of the published literature. Vaccine. 2012;30(45):6347-58.

12. Briggs AH, Wonderling DE, Mooney CZ. Pulling cost-effectiveness analysis up by its bootstraps: a non-parametric approach to confidence interval estimation. Health Econ. 1997;6:327-40.

13. Briggs A, Schulpher M, Claxton K. Decision modelling for health economic evaluation. Oxford: Oxford University Press; 2006.

14. Griffiths UK, Miners A. Economic evaluations of Haemophilus influenzae type b vaccine: systematic review of the literature. Expert Rev Pharmacoeconomics Outcomes Res. 2009;9(4): 333-46.

15. Griffiths UK, Korczak VS, Ayalew D, Yigzaw A. Incremental system costs of introducing combined DTwP-hepatitis B-Hib vaccine into national immunization services in Ethiopia. Vaccine. 2009;27(9):1426-32.

16. Lee BY, Assi TM, Rookkapan K, Connor DL, Rajgopal J, Sornsrivichai $\mathrm{V}$, et al. Replacing the measles ten-dose vaccine presentation with the single-dose presentation in Thailand. Vaccine. 2011;29(21):3811-7.

17. Pereira CC, Bishai D. Vaccine presentation in the USA: economics of prefilled syringes versus multidose vials for influenza vaccination. Expert Rev Vaccines. 2010;9(11):1343-9.

18. Gosbell IB, Gottlieb T, Kesson AM, Post JJ, Dwyer DE. Immunisation and multi-dose vials. Vaccine. 2010;28(40):6556-61.

19. Hutchins SS, Jansen H, Robertson SE, Evans P, Kim-Farley RJ. Studies of missed opportunities for immunization in developing and industrialized countries. Bull World Health Organ. 1993; 71(5):549.

20. Guichard S, Hymbaugh K, Burkholder B, Diorditsa S, Navarro C, Ahmed $\mathrm{S}$, et al. Vaccine wastage in Bangladesh. Vaccine. 2010;28(3):858-63.

21. Parmar D, Baruwa EM, Zuber P, Kone S. Impact of wastage on single and multi-dose vaccine vials: implications for introducing pneumococcal vaccines in developing countries. Human vaccines. 2010;6(3):270-8.

22. Lee BY, Norman BA, Assi TM, Chen SI, Bailey RR, Rajgopal J, et al. Single versus multi-dose vaccine vials: an economic computational model. Vaccine. 2010;28(32):5292-300.

23. Lorenson K, Garnett A, Kristensen D. Breakeven analysis for various human paopillomavirus vaccine presentations in Vietnam and in Uganda. Seattle: PATH; 2010.

24. Quiroga R, Halkyer P, Gil F, Nelson C, Kristensen D. A prefilled injection device for outreach tetanus immunization by Bolivian traditional birth attendants. Rev Panam Salud Pública. 1998;4(1): $20-5$.

25. Tsu VD, Luu HTT, Mai TTP. Does a novel prefilled injection device make postpartum oxytocin easier to administer? Results from midwives in Vietnam. Midwifery. 2009;25(4):461-5.

26. Wang L, Li J, Chen H, Li F, Armstrong GL, Nelson C, et al. Hepatitis B vaccination of newborn infants in rural China: evaluation of a village-based, out-of-cold-chain delivery strategy. Bull World Health Organ. 2007;85(9):688-94.

27. Sullivan SD, Mauskopf JA, Augustovski F, Caro JJ, Lee KM, Minchin M, et al. ISPOR Task-Force Report. Budget impact analysis-principles of good practice: report of the ISPOR 2012 Budget Impact Analysis Good Practice II Task Force. Value Health. 2014;17(1):5-14. 